\title{
Aging and the musculoskeletal system
}

\author{
David Hamerman \\ I heard the old, old men say, \\ "Everything alters \\ And one by one we drop away". \\ They had hands like claws, and their knees \\ Were twisted like the old thorn trees \\ By the waters \\ W B Yeats ${ }^{1}$
}

\section{Geriatric and rheumatological linkages: public health implications}

Editors in medical journals worldwide have selected aging as the 1997 Global Theme Issue. In proposing this article, the editors of the Annals have considered the importance and implications of the growth of the very elderly population in developed countries and the widespread prevalence of musculoskeletal conditions in this age group. Broadening the scope of this discussion from osteoarthritis, about which I have written in this journal earlier, ${ }^{2}$ to include musculoskeletal disorders, permits consideration of a range of interactive conditions that also affect soft tissues, tendons, and ligaments (fibromyalgia, tendinitis), bones (osteoporosis), the intervertebral discs (degeneration), and muscles (polymyalgia, myopathies). This article will focus primarily on aging associated conditions involving bones, muscles, and peripheral joints. Table 1 presents the unifying features of the musculoskeletal disorders. Their public health implications in elderly persons are enormous, and encompass (a) physical and social impacts from pain, limited mobility, reduced quality of life; (b) direct expenditures for diagnosis and treatment; (c) indirect economic costs from loss of participation in the labour force. ${ }^{3}$ Among impairments identified in the National Health Interview Survey in 1988, musculoskeletal disorders were the most frequently reported - almost 30 million in the US population. In 1992 the total cost of musculoskeletal and associated conditions for all ages was $\$ 149$ billion. The elderly incurred the largest share of the direct costs of medical care ( $\$ 51$ billion) with still substantial indirect costs caused by lost wages. ${ }^{4}$

Accepted for publication 17 July 1997

Table 1 Unifying features of aging and musculoskeletal disorders

Age associated increasing prevalence

Intrinsic part of the aging process - especially for bones and muscles

Part of the spectrum of chronic, non-fatal conditions

Range of symptomatic presentations - limited and localised to more chronic and widespread conditions Potential for impaired functional activities, disability, falls, and fractures
There are at least 26 million white women at risk for fractures by virtue of low bone mass or osteoporosis. ${ }^{5}$ Hip fracture incidence will continue to increase - an orthopaedic epidemicwith US expenditures in 1995 estimated at $\$ 13.8$ billion; fractures at other skeletal sites accounted for 36.9 per cent of health care expenditures nationally and yet have tended to be underestimated. ${ }^{6}$ The greater longevity of women compared with men results in older women spending more years living in the disabled state, for which arthritis is by far the most prevalent chronic condition. ${ }^{7}$ An estimated 60 per cent of the 65 to 74 year old group in the HANES I study had physician observed musculoskeletal disorders (joint complaints, pain in the back, neck, limited shoulder motion). ${ }^{8}$ Several authors emphasise that regional musculoskeletal disorders (for example, tendon lesions, soft tissue rheumatism) have been overlooked in the planning and provision of health care despite their increasing importance. ${ }^{9}$ Among elderly persons who have left the work force because of musculoskeletal injuries, 86 per cent of the total costs of such injuries resulted from the direct costs of medical care. In contrast, direct costs accounted for only 39 per cent of the total costs of musculoskeletal conditions not related to injury. ${ }^{4}$ Verbrugge and Patrick examined seven chronic conditions and their impact on US adults' activities and uses of medical services. Arthritis was the most common condition in middle and late life, and the most frequently cited cause of limitations, but had low visibility in biomedical research and health care funding because of 'low prominence in health services'. ${ }^{10}$ The costs to society of musculoskeletal impairments in terms of personal suffering, in limitations of activities, and in health expenditures, should serve as an imperative to health professionals, planners, and legislators, to consider means to promote new research initiatives, foster more extended care services, and encourage preventive strate- 
gies. The verse lines of W B Yeats cited above raise geriatric and rheumatological visions of decline and disability, a discouraging note, perhaps appropriate for the outlook almost a century ago. This article aims to project a more positive side for both disciplines based on advances in clinical and basic research that hold out prospects for therapeutic interventions - indeed preventive approaches - that may lead to improved health services and practices to promote a better quality of life for an aging society.

Prospects for intervention and prevention The interrelations of aging and components of the musculoskeletal system-muscles, bones, cartilage, soft tissues, tendons-are perhaps best understood in the context of the outcome of muscle strengthening regimens. Trials of exercise interventions ${ }^{1112}$ seek to define the most beneficial means to preserve joint (especially shoulder) mobility, stabilise bone density, improve muscle strength, gait and balance, and prevent falls in populations of well elderly persons, in older women who may be sedentary, and particularly in the 'frail elderly ${ }^{13}$ who constitute $10-20$ per cent of the older population and have a constellation of physical and mental conditions that place them at risk for adverse outcomes. Shoulder disorders with pain have high prevalence in surveys of community dwelling people, ${ }^{14}$ especially those over age $70,{ }^{15}$ reflecting tendon lesions and soft tissue rheumatism. ${ }^{9}$ Considerable progress has been made in defining mechanisms whereby various traumas induce modifications in tendon cell synthesis and matrix composition, providing a basis to pursue rationale therapeutic approaches. ${ }^{9}$ The term osteopenia is widely used to reflect the extent of bone mineral loss shown by bone density measurements $1 \mathrm{SD}$ below the young normal mean, ${ }^{5}$ but perhaps less familiar is the term sarcopenia - the age related loss in skeletal muscle mass-and its potential for reduced strength, yet the consequences are just as significant in the aging process. ${ }^{16}$ There are no widely available clinical means comparable to bone densitometry to measure aging related loss of muscle mass and its replacement by fat and connective tissue, although muscle strength that accompanies this can be measured. After age 30, there is a 3-5 per cent loss of muscle mass per decade, with a higher decline after age 60, and perhaps an even greater decline in muscle strength, reaching 30 per cent loss per decade after age $70 .{ }^{17}$ There appears to be predominantly loss of type 2 (fast twitch) fibres in selected muscles, caused in part by denervation and less successful reinnervation processes. ${ }^{18}$ Aerobic, endurance exercises (walking, jogging) that entail high repetition, are able to reduce coronary heart disease risk factors, but result in little gain in strength nor in increased bone mineral density at the proximal femur. Heavy resistance training entails a repetition maximum and is targeted to bone and muscle specific sites-that is, the femoral neck for fracture reduction, or the quadriceps for maintaining knee stability, gait, and balance. ${ }^{11}{ }^{19}$ Note that the targeting of exercises to bone and muscle sites is analogous in some respects to evaluating mobility and functional impairments (for example, in osteoarthritis) by specific, site directed tasks. ${ }^{7820}$ In a remarkable demonstration of the effects of progressive quadriceps resistance training in frail nursing home residents aged 86 to 96 years, muscle mass and strength increased, and time required to walk a measured distance decreased. ${ }^{21}$ These improvements were rapidly lost, however, with cessation of the exercise. Prolonged bed restthe converse of exercise-can produce profound loss of muscle mass, strength, and bone mineral density, ${ }^{22}$ and frail elderly persons are especially at risk for hip fractures during attempts at re-ambulation. Intensive exercise training carried out during bed rest may attenuate deconditioning. ${ }^{23}$ Community dwelling adults with symptomatic knee osteoarthritis (mean age 69) participated in aerobic or resistance training for an 18 month period with modest improvement in self reported pain and disability. ${ }^{24}$ Quadriceps weakness may be present in patients who have radiographic evidence of osteoarthritis but do not complain of knee pain. ${ }^{25}$ Preserving quadriceps strength over an extended time is likely to be a key aspect that may lessen the risk of developing osteoarthritis of the knee. Health practices that maintain ideal body weight, avoid obesity, and limit joint trauma are also thought to contribute to its 'primary prevention' ${ }^{26}$ Persons in middle age, recognising the benefits of health practices to maintain the integrity of the musculoskeletal system in those over 65, may be encouraged to adopt such practices that could result in more functional longevity decades later.

\section{Prospects for early diagnosis and new treatments}

Risk factors for osteoarthritis and osteoporosis - the most prevalent conditions of the aging skeleton-are generally well known. ${ }^{27}$ Newer diagnostic approaches that increase our understanding of the basic mechanisms involved in these conditions and offer the prospects for earlier, potentially remediable therapeutic interventions, are discussed here briefly and with limited references.

BIOCHEMICAL MARKERS OF BONE AND CARTILAGE TURNOVER

Such tests have perhaps come into more widespread use in osteoporosis than in osteoarthritis because of the availability of other correlative studies - such as bone mineral density measurements and analyses of the genetics of the vitamin D receptor (see below). High serum concentrations of osteocalcin and bone specific alkaline phosphatase reflect high bone turnover associated with bone formation, while collagen peptides in urine, particularly bone specific deoxypyridinoline cross links, reflect bone resorption. ${ }^{28}$ Cartilage and bone markers in osteoarthritis have been studied in relation to radiographic evidence of joint space narrowing, reflecting cartilage loss, and of 
subchondral sclerosis and the presence of osteophytes, reflecting bone formation-an 'uncoupling' of the normal balance of degradation and repair in these respective structures. ${ }^{29}$ In patients with diagnosed knee osteoarthritis on entry to one study, concentrations of serum hyaluronan and cartilage oligomeric matrix protein were associated with progression at five year follow up. ${ }^{30}$ Reduced serum concentrations of vitamin D may be a marker for progression of knee osteoarthritis. ${ }^{31}$

GENETIC ANALYSES

A relation between bone mineral density and polymorphism of the vitamin $\mathrm{D}$ receptor gene has been shown in a number of studies, especially on twins, by using restriction enzymes (Bsm1, Apa 1, and Taq 1) on the polymorphic regions. ${ }^{32}$ One form of polymorphism in subjects classified as BB (region broken by Bsm1) showed high serum concentrations of osteocalcin and vitamin D and reduced bone density in the femoral neck. However, not all studies have confirmed the prevalence and importance of the genetic association, especially in elderly women age 75 years or more, ${ }^{33}$ suggesting that findings may depend on many variables in the study population, including ethnic background, geographical origin, age, pre- or postmenopausal state, calcium intake, and body mass index. A recent meta-analysis of 16 published studies showed a modest effect of vitamin $\mathrm{D}$ receptor genotype on bone mineral density at the hip, spine, and radius, with a reduction of about two per cent at these sites in the BB compared with the bb genotype groups. ${ }^{34}$ Genetic and environmental factors that contribute to body weight at the age of one year may 'programme' the extent of bone mineral content in the same subjects 60-70 years later, with higher infancy weights projecting a better outcome. ${ }^{35}$ A genetic predisposition was observed for osteoarthritis with radiographical findings in the hands and knees in studies on female twin pairs aged $48-69$ years. $^{36}$

IMAGING AND DENSITOMETRIC MODALITIES Advances in the research use of quantitative magnetic resonance imaging make it possible to assess the state of cartilage, joint space width, and bone, in finger joints where changes can be followed up prospectively to distinguish aging from early findings of osteoarthritis, and as a clinical development tool to monitor new drugs affecting matrix turnover and repair. ${ }^{37}$ Dual energy $x$ ray absorptiometry has come into widespread clinical use to assess bone density in the femoral neck and spine in subjects at high risk for osteoporosis; however, generalised screening for this condition is not advocated at present. ${ }^{38}$

THERAPEUTIC INTERVENTIONS

The defining lesions in the osteoarthritic joint relate to cartilage fibrillation and loss, and subchondral new bone formation, as noted. The extent of spontaneous healing of cartilage in the early stage of osteoarthritis is uncertain; patients with clinical complaints in the joint who come to arthroscopy may show defects in the cartilage. The use of cells with chondrogenic potential, and growth factors such as transforming growth factor $\beta$ (TGF $\beta$ ) or fibroblast growth factors (FGFs) to stimulate cell proliferation and synthesis of matrix components, offer experimental approaches to repair cartilage defects without resorting to surgical debridement. A number of studies have indicated promising results. Infusion of basic type FGF into the joint of a rabbit appeared to repair defects limited to the cartilage, presumably by promoting chondrocyte proliferation and matrix synthesis. ${ }^{39}$ Chondrocytes obtained from a rabbit, or from a human patient, were amplified in cell culture and injected into the cartilage defect in the same animal or individual, with evidence of healing. ${ }^{41}$ The human patients in this study were age 14 to 48 with full thickness defects in cartilage. Fibrin matrices treated with TGF $\beta$ and implanted into cartilage defects in rabbit joints stimulated growth of synovial mesenchymal cells into the defect. ${ }^{42}$ Whether these cells have chondrogenic potential is not yet known. When defects are made in cartilage that penetrate into subchondral bone, a different situation prevails: blood vessels and mesenchymal cells from the marrow enter the blood clot that forms in the cartilage, and chondrogenesis occurs. However, the fibrocartilage that ultimately forms is not stable and deteriorates over time. New therapeutic approaches to increase bone formation in osteoporosis or to repair cartilage defects in osteoarthritis are likely to arise from a greater understanding of the influence of growth factors on these tissues or their progenitor mesenchymal stem cells. ${ }^{43}$ Techniques are available for isolating, preserving, and 'directing' the lineage of these stem cells, ${ }^{43}$ particularly with the use of components of the TGF $\beta$ superfamily, including bone morphogenetic proteins ${ }^{44}$ to promote development of osteoblasts, and cartilage derived morphogenetic protein ${ }^{45}$ to promote chondrocyte differentiation. The challenge for cartilage repair in vivo will be to stimulate growth of 'articular' chondrocytes ${ }^{45}$ and to limit vascular invasion that might lead to endochondral ossification.

Increased subchondral bone density in osteoarthritis has attracted much interest as the 'inverse' of bone loss in osteoporosis, ${ }^{46}$ yet its mechanisms and ultimate significance are unknown. ${ }^{47}$ Sclerosis and stiffness of the cancellous subchondral bone may act biomechanically to promote shearing forces that break down cartilage, ${ }^{48}$ although the calcified subchondral plate immediately below the articular cartilage was less stiff in osteoarthritis than normal and thus should absorb energy better. $^{49}$ In an aging monkey model spontaneously developing osteoarthritis, dense subchondral bone was found to precede cartilage degeneration. ${ }^{50}$ It is not clear at present whether therapeutic options can be developed to 'reduce' subchondral bone sclerosis and limit osteophyte formation in the knee and hip in osteoarthritis, and even if this were possible, what the long term outcome would be. 
Synovial membrane cells release cytokines, such as interleukin 1 and tumour necrosis factor into the joint cavity, ${ }^{51}$ with activation of cyclooxygenase (COX) enzymes that promote chondrocyte production of prostaglandins. COX1 is expressed in a more constant fashion in tissues such as the gastric mucosa, platelets and kidney, while COX2 is augmented in response to cytokines. ${ }^{52}$ Until recently, the available NSAIDs generally diminished prostaglandin synthesis by inhibition of COX1, with potent side effects on the kidney and gastric mucosa. As is well known, elderly persons with musculoskeletal complaints are at highest risk for NSAID toxicity yet it is for these people that the drugs are most widely prescribed. NSAIDs with more selective inhibition of COX2 may suppress inflammation in joints with perhaps fewer organ side effects. ${ }^{52}$ Disease modifying agents for osteoarthritis would prevent or retard cartilage matrix breakdown and are being explored in animal models. A number of orally active matrix metalloproteinase inhibitors have been tested for specific inhibitory activities against collagenase and stromelysin, and yet difficulties remain in their clinical application. ${ }^{53}$ Doxycycline inhibits the activity of collagenase in extracts of articular cartilage, prompting in vivo studies of this potentially disease modifying oral agent in a canine model of osteoarthritis; human clinical trials have also begun. ${ }^{54}$ However, as Brandt has noted 'all the tissues of the involved joint in osteoarthritis are abnormal. We should not dismiss the possibility that pharmacological, biological or physical measures that modify disease processes in subchondral bone, synovium, joint capsule, ligaments, or periarticular muscles will be more effective than a 'chondroprotective' drug'. ${ }^{54}$

Age related decline in the secretion of growth hormone, the resulting insulin-like growth factors, and adrenal and gonadal sex steroids, has raised consideration of treatment with these 'youthful hormones' 55 for elderly subjects who manifest debilitating conditions, including osteoporosis, to promote bone formation, increase physical vigour, and to reverse changes in body composition that constitute risk factors for disability and disease. However, at present, prospects for the clinical use of anabolic hormones for these purposes, at least judged by recent results with the administration of growth hormone in healthy older men, ${ }^{56}$ are not encouraging. Use of low dose IGF1 may have better prospects. ${ }^{57}$

\section{Aging at the cellular level: relevance to musculoskeletal disorders}

A recent review focused on the processes of biological aging rather than on diseases that inevitably seem to be associated with aging. ${ }^{58}$ Non-adaptive theories propose that aging arises through the indirect action of natural selection. A more specific version that Kirkwood termed the 'disposable soma theory' proposes that aging is a result of the accumulation of defects in macromolecules caused by limited capacity for tissue maintenance and repair. ${ }^{58}$ Less investment in repair than that required for perfect maintenance results in aging. Shorter lived species may also be those with less successful DNA repair mechanisms, higher rates of mutations, susceptibility to free radical damage, and related conditions associated with a loss of fidelity of gene regulation and protein synthesis. ${ }^{59}$

The aging of the organism is reflected at the cellular level by the renewal of haematopoietic and mesenchymal stem cells, and by their differentiation and maturation. ${ }^{60}$ The derived mature cells (blood cell lineage and osteoclasts, myoblasts, adipose cells, fibroblasts, osteoblasts, and chondroblasts), proliferate, synthesise their characteristic components, and ultimately undergo senescence or follow a path to programmed cell death. These complex cell changes are at all times under genetic control, influenced by growth factors in the environment that arrive via the circulation or are produced by and interactive with the cells. ${ }^{61}$ Some stem cells can be instructed to choose one pathway of differentiation by growth factors, while others make this choice in some other predetermined way in which growth factors act as survival factors or mitogens for committed cells. ${ }^{60} \mathrm{~A}$ great deal has been learned recently about the development of osteoblasts in bone and chondrocytes in cartilage. As the osteoblast differentiates during embryogenesis from a multipotent mesenchymal cell, a transcription factor (see below) called $C b f a 1$ upregulates the expression of osteoblast related genes. ${ }^{62}$ Among the early response genes are $c$-fos and $c$-jun; then genes appear coding in temporal sequence for histones, collagen type 1, alkaline phosphatase, osteopontin, and osteocalcin-a protein expressed at the peak of mineralisation-after which the matrix is remodelled. ${ }^{63}$ A sequence of genetic events occurs in proliferating chondrocytes, including expression of high concentrations of the secreted protein parathyroid hormone related peptide and then expression of a gene called Indian hedgehog (Ihh) as the chondrocytes become fully hypertrophic. This process is under further feedback control to prevent non-differentiated chondrocytes from moving down the hypertrophic pathway, thereby controlling the extent of longitudinal bone growth. ${ }^{64}$

Cells in a state of senescence are no longer able to replicate, ${ }^{65}$ but they are not dead; indeed they are resistant to programmed cell death (apoptosis). ${ }^{66}$ Senescent cells show changed synthetic functions, such as increased collagenase production and reduced synthesis of tissue inhibitor of metalloproteinasesconditions that modify the tissues and organs and limit repair, as noted above, and contribute to 'aging' processes in situ in ways that are not really understood. Senescent cells have reached the end of their replicative life span because they are unable to progress from the $G_{1}$ to $S$ phase in the cell cycle. ${ }^{65}$ Mitogenic growth factors that induce quiescent cells to begin to traverse the cell cycle from $G_{1}$ to $S$ and beyond, still will not stimulate senescent cells to do so. ${ }^{65}$ The fundamental reasons for this block to progression in the cell cycle for senes- 
cent cells are not fully known. When senescent cells are fused with replicating cells, cell division stops, and thus senescence is a dominant genetic trait. ${ }^{67}$ Information is emerging on modifications in a number of cell cycle regulators that may account in part for the senescent state: there seems to be loss of certain early response genes, overexpression of two inhibitors (p21 and p16) of critical growth promoting cyclin dependent kinases, ${ }^{689}$ and uninhibited activity of growth (tumour) suppressor genes. ${ }^{65}$ New insights have also become apparent relating to modifications in replicating cells that are part of the 'games that genes, viruses, and cells play': a mutant ras oncogene introduced into replicating cells considerably slows down their growth and induces, prematurely as it were, a senescence-like state. ${ }^{70}$

Developments in molecular genetics have provided insights on modifications in collagen genes that result in skeletal growth abnormalities in humans. Two examples from many ${ }^{7172}$ are type I collagen gene mutations (COL $1 \mathrm{~A} 1$ and COL 1A2), associated with a syndrome of osteogenesis imperfecta; and type II collagen gene mutations (COL 2A1), which result in a range of spondyloepiphyseal dyplasias. A number of these latter syndromes have been described as 'type II collagenopathies. ${ }^{, 72}$ One of the COL 2A1 mutations is manifested in affected families by normal stature but with premature primary generalised osteoarthritis. ${ }^{73}$ While opening up a new and important dimension in research, it has been suggested that most of the familial cases of osteoarthritis are not likely to be attributable to type II collagen mutations. $^{29}$

In animal models, an even wider range of genetic modifications - spontaneous or induced-are particularly instructive for observing the resulting phenotypic manifestations on the developing musculoskeletal system as the animal ages. Skeletal dysplasias have been the most intensively investigated with exciting new findings on genetic control of skeletal growth, ${ }^{6271}$ but many of these studies are beyond the scope of this article. Table 2 focuses on selected examples of genetic modifications that result in phenotypic changes in the musculoskeletal system. The animal models of osteopetrosis, while an uncommon human clinical disorder, are important to illustrate how various genetic modifications at different developmental stages of osteoclast lineage and function result in impaired bone resorption and a similar phenotypic expression in the mouse - that is, dense bones. ${ }^{74} \mathrm{~A}$ spontaneous null mutation in the gene for macrophage colony stimulating factor-1 in $o p / o p$ mice results in an inactive growth factor that normally is necessary for the maturation and function of certain cells of the mononuclear phagocytic system: osteoclasts and macrophages in bone, and the type A (macrophage-like) cell in the synovial membrane. ${ }^{7576}$ The osteopetrotic $(o p)$ mouse model has been considered relevant to human osteoarthritis by virtue of the persistence of dense subchondral bone as the animal ages, during which time diaphyseal bone is restored to normal. ${ }^{47}$ Mice rendered deficient in either of two cellular protooncogenes, $\mathrm{c}-s \mathrm{sc}^{77}$ or c- $f \circ s{ }^{78}$ show osteopetrosis resulting from impaired osteoclastic bone resorption, or failure of osteoclast lineage development, respectively. c-fos, which encodes a transcription factor, and c-src a membrane associated protein kinase, have the potential to become oncogenes when mutated. An insertional mutation in a mouse gene encoding a transcription factor termed $m i \mathrm{TF}$ results in microphthalmia, and induces formation of osteoclasts without ruffled borders and with poor bone resorbing capabilities, leading to osteopetrosis. ${ }^{79}$ Mice genetically engineered to overexpress a protein the authors called osteoprotegerin-a member of the TNF receptor superfamily - exhibit a more benign form of osteopetrosis compared with those above, with a decrease in osteoclast numbers, apparently because of failure in maturation. ${ }^{80}$ Moreover, ovariectomised mice treated with osteoprotegerin maintained bone density. Mice deficient in PU.1, another transcription factor, lose a common haematopoietic progenitor for osteoclasts and macrophages, and this defect 'may represent the earliest developmental osteopetrotic mutant yet described'-that is, earlier than mutations in CSF-1, c-fos, or c-src. ${ }^{81}$ On the other hand, overexpression of c-fos results in unrestrained osteochondral cell growth and sarcoma-like bone tumours. ${ }^{82}$ Mice with a deficient osteocalcin gene-a protein

Table 2 Genetic modifications and musculoskeletal manifestations in some mouse models relevant to human aging

\begin{tabular}{|c|c|c|}
\hline Model/manifestations & Genetic conditions & References \\
\hline Osteopetrosis & $\begin{array}{l}\text { Spontaneous null mutation - CSF-1 gene } \\
\text { c-src disruption } \\
\text { c- } f o s \text { disruption } \\
m i \text { insertional mutant } \\
\text { Osteoprotegerin expression }{ }^{\star} \\
\text { PU.1 deletion }\end{array}$ & $\begin{array}{l}75 \\
77 \\
78 \\
79 \\
80 \\
81\end{array}$ \\
\hline Bone sarcomas & c-fos overexpression & 82 \\
\hline Increased bone density and functional quality & Induced osteocalcin deficiency ${ }^{\star}$ & 83 \\
\hline Spontaneous calcification in arteries and cartilage, osteopenia, fractures & Disrupted GLA protein $(\mathrm{Mgp})^{\star}$ & 84 \\
\hline Osteoporosis resistance after ovariectomy & $\begin{array}{l}\text { Induced null mutation in IL6 gene } e^{\star} \\
\text { Injection of integrin-like compound blocks osteoclast action }\end{array}$ & $\begin{array}{l}85 \\
86\end{array}$ \\
\hline Osteopenia & Disruption of oestrogen receptor gene & 88 \\
\hline Osteoporosis & Augmented expression of IL4 & 89 \\
\hline Osteoarthritis & Aging C 57BL mouse & 90 \\
\hline Muscular dystrophy & Aging SJL/J mouse & 91 \\
\hline Failure of skeletal muscle development & $\begin{array}{l}\text { Induced deficiency of myo D and myf- } 5 \\
\text { Splotch mouse lacks Pax-3 gene }\end{array}$ & 92 \\
\hline
\end{tabular}

^ Areas for potential clinical application (see text). 
synthesised by osteoblasts in bone-show increased bone formation and improved bone quality. In this model, osteoclasts function normally, or even to a greater extent: ovariectomised osteocalcin deficient mice develop a more severe osteoporosis with oestrogen depletion than their normal ovariectomised littermates. ${ }^{83}$ Matrix GLA protein $(\mathrm{Mgp})$ is a mineral binding, extracellular matrix protein synthesised by vascular smooth muscle cells and by proliferating chondrocytes; in both instances their matrices are normally uncalcified. Mgp deficient mice, as they age, exhibit vascular and cartilage calcifications. ${ }^{84}$ Thus, these latter two 'deficiency' models show the normal capacity of osteocalcin to limit bone formation, and of Mgp to limit calcification processes in extracellular matrices of arterial blood vessels and cartilage. Future therapeutic interventions might be to develop antagonists to osteocalcin to promote bone formation, and agonists to Mgp to limit vascular and cartilage calcification. Mice with a targeted null mutation in the interleukin 6 gene maintain bone density after ovariectomy because of deficiency in osteoclast function despite oestrogen lack. $^{85}$ Certain osteoclast membrane molecules, called integrins, attach to matrix components, such as fibronectin or osteopontin, and initiate bone resorption. This process seems to be blocked by a synthetic integrin tested in vitro or injected into rats, which were then protected from bone loss after oophorectomy. ${ }^{86}$ Targeted disruption of the oestrogen receptor gene results in mice with osteopenia. ${ }^{87}$ These authors also describe a single clinical case, that of a 28 year old man with a mutated oestrogen receptor gene, who showed oestrogen insensitivity, pronounced reduced bone density (3.1 SD below age matched women), and a bone age comparable to 15 years. ${ }^{88}$ Augmented expression of the gene for interleukin 4 in mice results in osteoporosis because osteoblastic bone formation is more severely decreased than osteoclastic bone resorption. ${ }^{89}$ One species of aging mice (C 57BL) spontaneously develops osteoarthritis $^{90}$; another (SJL/J), a form of muscular dystrophy. ${ }^{91}$ Deficiency in certain genes that control myogenesis results in various types of failure of muscle development. ${ }^{92}$

A number of transcription factors have been classified with respect to their structural/ functional motifs in relation to the aging of bone $^{93}$ and can be considered briefly in the light of genetic modifications shown in table 2 . Many transcription factors become active in response to signals generated from the extracellular environment, and thus transduce these external signals to nuclear DNA to control the expression of specific genes that regulate differentiation processes. ${ }^{71}$ The c-fos protooncogene is a member of the so called leucine zipper family of transcription factors. The c-fos/leucine zipper motif is important for dimer formation with c-jun, a complex essential for forming the AP1 transcription factor complex, which in turn binds to the AP1 consensus sequence in the regulatory region of many genes, and stimulates their transcrip- tion. ${ }^{94}$ Another family of transcription factors that have a fundamental role in the genetic expression of aging human bone are the steroid/nuclear hormone receptor family characterised by the presence of zinc fingers in the DNA binding domain. These constitute receptors for a number of key small molecules, such as vitamin $\mathrm{D}$, oestrogen, retinoic acid, and glucocorticoids. Interaction of these nuclear receptors with the AP1 transcription factor complex may account for the 'reciprocal relation' of bone cell development, whereby increased AP1 activity (c-fos, c-jun binding) in proliferating osteoblasts represses vitamin D mediated upregulation of osteoblastic differentiated functions, such as osteocalcin synthesis. ${ }^{95}$ A third family of transcription factors consist of the basic helix-loop-helix (bHLH) family. They are of particular importance because the expression of some of their components - myogenin, Myo D and Myf-5 (see table 2), and Id- are concerned with the lineage development and differentiated functions of myoblasts ${ }^{92}$ and osteoblasts, ${ }^{95}$ respectively, in muscle and bone formation. The mi locus, which is disrupted by an insertion (table 2), encodes a bHLH transcription factor, $m i \mathrm{TF}$, as noted. ${ }^{79}$ These are just some examples of transcription factors that regulate the replicating cell's development and synthetic functions, some of which become modified in the growth arrested state of the senescent cell. ${ }^{96}$ Significant molecular insights now exist concerning the differentiation of mesenchymal cells and their maturation into cells of the myogenic, osteogenic, and chondrogenic lineage: the bHLH transcription factors, the Cbfa1 gene family, and the $\mathrm{Ihh} / \mathrm{PTHrP}$ regulatory system, respectively, as discussed above.

\section{Conclusions}

In the next several decades our society will experience an unprecedented challenge arising from the growth of the older population, particularly those surviving to very advanced age. Musculoskeletal disorders are widespread in elderly persons and have important public health implications. This article considers these challenges as opportunities, and presents some emerging health practices, particularly exercise programmes, that may extend a vigorous life style for older persons. Also discussed are newer diagnostic tests, and research studies that elucidate the development, maturation, and senescence of connective tissue cells in the aging process. Basic research is increasingly attentive to potential clinical applications, with prospects for early detection and therapeutic interventions that may ameliorate musculoskeletal disorders-especially osteoarthritis and osteoporosis - that exact such a high toll in suffering and expenditures. The combined endeavours of health providers and research scientists can become united in a common goal for the 'whole health experience' of older persons ${ }^{97}$ : not so much to extend the duration of life, but rather to improve its quality and preserve its vitality for a longer time. 
The author is most grateful to Judith Campisi, Ph D, Department of Cancer Biology, Life Sciences Division, Berkeley
Laboratory, University of California, for critical review of the description of cellular senescence in this paper.

1 Rosenthal M L, ed. Selected poems and two plays of William Butler Yeats. New York: MacMillan Publishing, 1962: 30.

2 Hamerman D. Clinical implications of osteoarthritis and ageing. Ann Rheum Dis 1995;54:82-5.

3 Praemer A, Furner S, Rice D P. Musculoskeletal conditions in the United States. Park Ridge, IL: American Academy of Orthopaedic Surgeons, 1992.

4 Yelin E, Callahan L F. The economic cost and social and psychological impact of musculoskeletal conditions. $\mathrm{Ar}-$ thritis Rheum 1995;38:1351-62.

5 Melton L J, III. How many women have osteoporosis now? J Bone Miner Res 1996;11:1205-8.

6 Fox N R, Chan J K, Thames M, Melton L J, III. Medical expenditures for the treatment of osteoporotic fractures in the United States in 1995: report from the National Osteoporotic Foundation. J Bone Miner Res 1997;12:24-35.

7 Fried L P, Guralnik J M. Disability in older adults: evidence regarding significance, etiology, and risk. J Am Geriatr Soc 1997;45:92-100

8 Jette A M. Musculoskeletal impairments and associated physical disability in the elderly: insights from epidemiological research. In: Buckwalter J A, Goldberg V M, Woo S L-Y, eds. Musculoskeletal soft-tissue aging: impact on mobility. Rosemont IL: American Academy of Orthopaedic Surgery, 1993: 7-22

9 Cawston T E, Riley G P, Hazleman B L. Tendon lesions and soft tissue rheumatism - great outback or great opportunity? Ann Rheum Dis 1996;55:1-3.

10 Verbrugge L M, Patrick D L. Seven chronic conditions: their impact on US adults' activity levels and use of medical services. Am J Public Health 1995;85:173-82.

11 Yarasheski K E. Effect of exercise on muscle mass in the elderly. In: Perry H M, III, Morley J E, Coe R M, eds. Aging and musculoskeletal disorders. New York: Springer Publishing, 1993: 199-213.

12 Buchner D M, Cress M E, Wagner E H, de Lateur B J, Price R, Abrass I B. The Seattle FICSIT/MoveIt study: the effect of exercise on gait and balance in older adults. J Am Gefrect of exercise on gait and

13 Fried L P, Williamson J D, Kasper J. The epidemiology of frailty: scope of the problem. In: Perry H M, III, Morley J E, Coe R M, eds. Aging and musculoskeletal disorders. New York: Springer Publishing, 1993: 3-15.

14 Pope D P, Croft P R, Pritchard C M, Silman A J. Prevention of shoulder pain in the community: the influence of case definition. Ann Rheum Dis 1997;56:308-12.

15 Chard M D, Hazleman R, Hazleman B L, King R H, Reiss B B. Shoulder disorders in the elderly: a community survey. Arthritis Rheum 1991;34:766-9.

16 Evans W J. What is sarcopenia? J Gerontol 1995;50A:5-8.

17 Nair K S. Muscle protein turnover: methodological issues and the effect of aging. J Gerontol 1995;50A:107-12.

18 Larsson L. Motor units: remodeling in aged animals. J Gerontol 1995;50A:91-5.

19 Bassey E J. Exercise in primary prevention of osteoporosis in women. Ann Rheum Dis 1995;54:861-2.

20 Guccione A A, Felson D T, Anderson J J, Anthony J A Zhang Y, Wilson P W F, et al. Specific diseases and their effects on the functional limitations of elderly in the Frameffects on the functional limitations of elderly in the

21 Fiatarone M A, Marks E C, Ryan N D, Meredith C N, Lipsitz L A, Evans W J. High-intensity strength training in nonagenarians: effects on skeletal muscle. JAMA 1990 263:3029-34.

22 Bloomfield SA. Changes in musculoskeletal structure and function with prolonged bed rest. Med Sci Sports Exerc 1997;29:197-206.

23 Greenleaf J E. Intensive exercise training during bed rest attenuates deconditioning. Med Sci Sports Exerc 1997; 29:207-15

24 Ettinger W H, Burns R, Messier S P, Applegate W, Rejeski $\mathrm{W} \mathrm{J}$, Morgan $\mathrm{T}$, et al. A randomized trial comparing aerobic exercise and resistance exercise with a health education program in older adults with knee osteoarthritis. JAMA 1997;277:25-31.

25 Slemenda C, Brandt K D, Heilman D K, Mazzuca S, Braunstein E M, Katz B P, et al. Quadriceps weakness and
osteoarthritis of the knee. Ann Intern Med 1997;128:97104 .

26 Hochberg M C. Epidemiologic considerations in the primary prevention of osteoarthritis. J Rheumatol 1991, 18:1438-40

27 Hamerman D. The aging skeleton - osteoarthritis and osteoporosis. In: Hamerman D, ed. Osteoarthritis. Public health implications for an aging population. Baltimore: Johns Hopkins University Press, 1997: 99-121.

28 Calvo M S, Eyre D R, Gundberg C M. Molecular basis and clinical application of biological markers of bone turnover. Endocr Rev 1996;17:333-68.

29 Kraus V B. Pathogenesis and treatment of osteoarthritis. Med Clin North Am 1997; 81:85-112.

30 Lohmander L S, Felson D T. Defining the role of molecular markers to monitor disease, intervention, and cartilage breakdown in osteoarthritis. J Rheumatol 1997;24:782-5.

31 McAlindon T E, Felson D T, Zhang Y, Hannan M T, Aliabadi P, Weissman B, et al. Relation of dietary intake and serum levels of vitamin D to progression of osteoarthritis of the knee among participants in the Framingham study. Ann Intern Med 1996;125:353-9.
32 Fujita T. Vitamin D in the treatment of osteoporosis revisited. Proc Soc Exp Biol Med 1996;212:110-5.

33 Vandevyer C, Wylin T, Cassiman J J, Rous J, Geusens P. Influence of the vitamin D receptor gene alleles on bone mineral density in postmenopausal and osteoporotic women. J Bone Miner Res 1997;12:241-7.

34 Cooper G S, Umbach D M. Are vitamin D receptor polymorphisms associated with bone mineral density? A meta-analysis. J Bone Miner Res 1996;11:1841-9.

35 Cooper C, Fall C, Egger P, Hobbs R, Eastell R, Barker D. Growth in infancy and bone mass in later life. Ann Rheum Dis $1997 ; 56: 17-21$.

36 Spector T D, Cicuttini F, Baker J, Loughlin J, Hart D. Genetic influences on osteoarthritis in women: a twin study. BMJ 1996;312:940-9.

37 Hall L D, Watson P J, Tyler J A. Magnetic resonance imaging and the progression of osteoarthritis, osteoporosis, and aging. In: Hamerman D, ed. Osteoarthritis. Public health implications for an aging population. Baltimore: Johns Hopkins University Press, 1997

38 Johnston C C, Jr. Development of clinical practice guidelines for prevention and treatment of osteoporosis. Calcif Tissue Int 1996;59 (suppl 1):S30-3.

39 Cuevas P, Burgos J, Baird A. Basic fibroblast growth factor (FGF) promotes cartilage repair in vivo. Biochem Biophys Res Commun 1988;156:611-8.

40 Brittberg M, Nilsson A, Lindahl A, Ohlsson C, Peterson L. Rabbit articular cartilage defects treated with autologous cultured chondrocytes. Clin Orthop 1996;326:270-83.

41 Brittberg M, Lindahl A, Nilsson A, Ohlsson C, Isaksson O, Peterson L. Treatment of deep cartilage defects in the knee with autologous chondrocyte transplantation. N Engl J Med 1994;331:889-95.

42 Hunziker E B, Rosenberg L C. Repair of partial-thickness defects in articular cartilage: cell recruitment from the synovial membrane. J Bone Joint Surg 1996;78A:721-33.

43 Bruder S P, Jaiswal N, Haynesworth S E. Growth kinetics, self-renewal, and the osteogenic potential of purified human mesenchymal stem cells during extensive subcultivation and followin

44 Reddi A H. Cartilage morphogenesis: role of bone and cartilage morphogenetic proteins, homeobox genes and tilage morphogenetic proteins, homeobox genes

45 Luyten F P. Cartilage-derived morphogenetic proteins. Key regulators in chondrocyte differentiation? Acta Orthop Scand 1995;66 (suppl 266):51-4.

46 Dequeker J, Boonen S, Aerssens J, Westhoven R. Inverse relationship osteoarthritis-osteoporosis: What is the evidence? What are the consequences? Br J Rheumatol 1996; 35: $813-20$

47 Hamerman D, Stanley E R. Implications of increased bone density in osteoarthritis. J Bone Miner Res 1996; 11:1205-8.

48 Radin E L, Burr D B, Caterson B, Fyhrie D, Brown T D, Boyd R D. Mechanical determinants of osteoarthrosis. Semin Arthritis Rheum 1991;21 (suppl 2):12-21.

$49 \mathrm{Li} \mathrm{B}$, Aspden R M. Mechanical and material properties of the subchondral bone plate from the femoral head of patients with osteoarthritis or osteoporosis. Ann Rheum Dis 1997;56:247-54

50 Carlson C S, Loeser R F, Purser C B, Gardin J F, Jerome C P. Osteoarthritis in cynomolgus macaques III. Effects of age, gender, and subchondral bone thickness on the severity of the disease. J Bone Miner Res 1996;11:1209-17.

51 Smith M D, Triantafillou S, Parker A, Youssef P P, Coleman $M$. Synovial membrane inflammation and cytokine production in patients with early osteoarthritis. J Rheumatol 1997;24:365-71.

52 Fenner $\mathrm{H}$. The pharmaceutical industry and therapeutic approaches to osteoarthritis in the next decade. In: Hamerman D, ed. Osteoarthritis. Public health implications for an aging population. Baltimore: Johns Hopkins University Press, 1997: 230-44.

53 Vincenti P M, Clark I M, Brickerhoff C E. Using inhibitors of metalloproteinases to treat arthritis. Easier said than done? Arthritis Rheum 1994;37:1115-26.

54 Brandt K D. Putting some muscle in osteoarthritis. Ann Intern Med 1997;128:154-6.

55 Orlander P R, Nader S. Youthful hormones. Lancet 1996;348 (suppl II):6

56 Papadakis M A, Grady D, Black D, Tierney M J, Gooding G A W, Schambelan M, et al. Growth hormone replacement in healthy older men improves body composition but not functional ability. Ann Intern Med 1996;124:708-16.

57 Ghiron L J, Thompson J L, Holloway L, Hintz R L, Butterfield G E, Hoffman A R, et al. Effects of recombinant insulin-like growth factor- 1 and growth hormones on bone turnover in elderly women. J Bone Miner Res 1995; 10:1844-52.

58 Kirkwood T B L, Wolff S P. The biological basis of ageing. Age Ageing 1995;24:167-71.

59 Gilchrest B A, Bohr V A. Aging processes, DNA damage, and repair. FASEB J 1997;11:322-30.

60 Morrison S J, Shah N M, Anderson D J. Regulatory mechanisms in stem cell biology. Cell 1997;88:287-98.

61 Taipale J, Keski-Oja J. Growth factors in the extracellular matrix. FASEB J 1997;11:51-9.

62 Rodan G A, Harada S. The missing bone. Cell 1997; 89:677-80.

63 Stein G S, Lian J B, Stein J L, Van Wijnen A J, Montecino M. Transcriptional control of osteoblast growth and differentiation. Physiol Rev 1996;76:593-629. 
64 Vortkamp A, Lee K, Lanske B, Segre G V, Kronenberg H $\mathrm{M}$, Tabin C J. Regulation of rate of cartilage differentiation by Indian hedgeh

65 Campisi J, Dimri G, Hara E. Control of replicative senescence. In: Schneider E, Rowe J, eds. Handbook of the biology of aging. 4th ed. New York: Academic Press, 1996: 121-49.

66 Wang E. Senescent human fibroblasts resist programmed cell death, and failure to suppress $b c l 2$ is involved. Cancer Res 1995;55:2284-92.

67 Hensler P, Pereira-Smith O M. Human replicative senescence. A molecular study. Am J Pathol 1995:147:1-8.

68 Noda A, Ning Y, Venable S F, Pereria-Smith O M, Smith J R. Cloning of senescent cell derived inhibitors of DNA synthesis using an expression screen. Exp Cell Res 1994;211:90-8.

69 Hara E, Smith R, Parry D, Tahara H, Peters G. Regulation of p16 (CdkN2) expression and its implications for cell immortalization and senescence. Mol Cell Biol 1996; 16:859-67.

70 Weinberg $\mathrm{R} \mathrm{A}$. The cat and mouse games that genes, viruses, and cells play. Cell 1997;88:573-5

71 Erlebacher A, Filvaroff E H, Gitelman S E, Derynck R. Toward a molecular understanding of skeletal development. Cell 1995;80:371-8.

72 Mundlos S, Olsen B R. Heritable diseases of the skeleton. Part II: Molecular insights into skeletal development matrix components and their homeostasis. FASEB J 1997; 11:227-33.

73 Williams C J, Jimenez S A. Heredity, genes, and osteoarthritis. Rheum Dis Clin North Am 1993;19:523-43.

74 Popoff S N, Marks S C, Jr. The heterogeneity of the osteopetroses reflects the diversity of cellular influences during petroses refects the diversity of cellular influ

75 Pollard J W, Stanley E R. Pleiotropic roles for CSF-1 in development defined by the mouse mutation osteopetrotic (op). Adv Dev Biochem 1996;4:153-93.

76 Cecchini M G, Dominguez M G, Mocci S, Wetterwald A, Felix R, Fleisch H, et al. Role of colony stimulating factor-1 in the establishment and regulation of tissue macfactor-1 in the establishment and regulation of tissue macrophages during postnatal devel

77 Soriano P, Montgomery C, Geske R, Radley A. Targeted disruption of the c-src proto-oncogene leads to osteopetrosis in mice. Cell 1991;64:693-702.

78 Johnson R S, Spiegelman B M, Papaioannou V. Pleiotropic effects of a null mutation in the c-fos proto-oncogene. Cell 1992;71:577-86.

79 Hughes M J, Lingrel J B, Krakowsky J M, Anderson K P. A helix-loop-helix transcription factor-like gene is located at the $m i$ locus. J Biol Chem 1993;268:20687-90.

80 Simonet W S, Lacey D L, Dunstan C R, Kelley M, Chang M S, Lüthy R, et al. Osteoprotegerin: a novel secreted protein involved in the regulation of bone density. Cell 1997; 89:309-19.

81 Tondravi M M, McKercher S R, Anderson K, Erdmann J M, Quiroz M, Makl R, et al. Osteopetrosis in mice lacking
haematopoietic transcription factor PU.1. Nature 1997; haematop $81-4$.
82 Rüther V, Garber C, Komitowski D, Müller R, Wagner E F. Deregulated c-fos expression interferes with normal bone development in transgenic mice. Nature 1987;325:412-6.

83 Ducy P, Desbois C, Boyce B, Pinero G, Story B, Dunstan C, et al. Increased bone formation in osteocalcin-deficient mice. Nature 1996;382:448-52.

84 Luo G, Ducy P, McKee M D, Pinero G J, Loyer E, Behringer R B, et al. Spontaneous calcification of arteries and cartilage in mice lacking matrix GLA protein. Nature 1997;386:78-81.

85 Poli V, Balena R, Fattori E, Markatos A, Yamamoto M, Tanaka $\mathrm{H}$, et al. Interleukin- 6 deficient mice are protected from bone loss caused by estrogen depletion. EMBO J 1994;13:1189-96.

86 Engelman V W, Nickols G A, Ross F P, Horton M A, Griggs $\mathrm{D} W$, Settle S L, et al. A peptidomimetic antagonist of the $\alpha_{\mathrm{v}} \beta_{3}$ integrin inhibits bone resorption in vitro and prevents osteoporosis in vivo. J Clin Invest 1997;99:2284-92.

87 Korach K S, Couse J F, Curtis S W, Motley ST, Teitelbaum SL, Jepsen KJ, et al. Estrogen receptor gene disruption: SL, Jepsen KJ, et al. Estrogen receptor gene disruption: phenotypes. Recent Prog Horm Res 1996;51:159-85.

88 Smith E P, Boyd J, Frank G R, Takahashi H, Cohen R M, Specter $\mathrm{B}$, et al. Estrogen resistance caused by a mutation in the estrogen receptor gene in a man. $\mathrm{N}$ Engl J Med 1995;331: 1056-61.

89 Lewis D B, Liggitt H D, Effman E L, Washburn TF, Lindzey J, Kimbro KS, et al. Osteoporosis induced in mice by overproduction of interleukin 4. Proc Natl Acad Sci by overproduction

90 Burton-Wurster N, Todhunter R J, Lust G. Animal models of osteoarthritis. In: Woessner J F, Jr, Howell D S, eds. foint cartilage degradation. Basic and clinical aspects. New York: Marcel Dekker, 1993: 347-84.

91 Weller A H, Magliato S A, Bell K P, Rosenberg N L. Spontaneous myopathy in the SJL/J mouse: pathology and strength loss. Muscle Nerve 1997;20:72-82.

92 Rawls A, Olson E N. MyoD meets its maker. Cell 1997;89:5-8.

93 Young M F. Transcription and aging of human bone tissue. Calcif Tissue Int 1995;56 (suppl 1):S39-40.

94 Angel P A, Karin M. The role of Jun, Fos and the AP-1 complex in cell-proliferation and transformation. Biochim Biophys Acta 1991;1072:129-57.

95 Siddhanti S R, Quarles L D. Molecular to pharmacologic control of osteoblast proliferation and differentiation. $\mathrm{J}$ Cell Biochem 1994;55:310-20.

96 Hara E, Uzman J A, Dimri G P, Nehlin J O, Testori A, Campisi J. The helix-loop-helix protein Id-1 and a retinoblastoma protein binding mutant of SV40 T antigen synergize to reactivate DNA synthesis in senescent human fibroblasts. Dev Genet 1996;18:161-72.

97 Verbrugge L M. Recent, present, and future health of American adults. Annu Rev Public Health 1989;10:33361. 